Original article

\title{
Assessment of malnutrition and its underlying causes among vulnerable populations dwelling in the urban slums of Nongstoin Town, Meghalaya
}

\author{
Tenneychell Khongrangjem ${ }^{\mathrm{a}, *}$, Amphivia Marwein ${ }^{\mathrm{b}}$ \\ ${ }^{\text {a }}$ District Urban Health Consultant, District Medical and Health Office, Nongstoin, Meghalaya, India \\ ${ }^{\mathrm{b}}$ Medical and Health Officer In-charge, Urban PHC, Nongstoin, Meghalaya, India
}

\section{A R T I C L E I N F O}

\section{Keywords:}

Assessment

Malnutrition

Vulnerable population

Urban slum

\begin{abstract}
A B S T R A C T
Introduction: Malnutrition in the vulnerable groups of children and pregnant women was observed to be one of the major factors for child and maternal mortality. The study aimed at evaluating the nutritional status as well as underlying causes of malnutrition among children and pregnant women living in urban slums of Nongstoin Town, West Khasi Hills District, Meghalaya.

Materials and methods: A cross-sectional study design with time bound enumeration was conducted in the urban slum of Nongstoin among 420 under five children and 88 pregnant women from June-August 2018 using a semistructured questionnaire quantifying the study objectives and standard assessment tools. The collected data was entered and analysed using SPSS (Statistical Package for the Social Sciences) version 16.

Results: Out of 420 participants 238(56.67\%) children found severely malnourished and remaining 182(43.33\%) of children were not in good health, most of them were found to have border line malnutrition and 49(55.68\%) pregnant women were found to be moderate anaemic (Hb level:6-9 mg/dl) and 3(3.4\%) pregnant women found to be having normal haemoglobin level ( $\mathrm{Hb}>12 \mathrm{mg} / \mathrm{dl})$.

Conclusion: Poor health hygiene, inadequate sanitation and unsafe drinking water facilities were found to be the underlying causes of Malnutrition. Most of the children and pregnant women in the study were poor in nutritional status. There is an urgent need for developing a program such as skills-based nutrition education and healthy eating habit.
\end{abstract}

\section{Introduction}

Deficiency in nutrition can lead to both acute as well as chronic malnutrition and later causes long term illnesses and even death. Anaemia during pregnancy is one of the causes of maternal mortality. In the context of severe vulnerability, children under five years of age and pregnant women are at most risk. Current statistics shows that $44 \%$ of children under five years of age are underweight, $72 \%$ infants and $52 \%$ pregnant women are having anaemia. ${ }^{1}$ The urban slum dwellers besides the poor socio-economic living conditions and the deficiency of essential nutrients, their lives are at increased risk of morbidity and mortality. The cities and towns are also expanding but the sheer volume of people compromises the ability of the city to meet their basic needs. ${ }^{2}$ A large proportion of this migrating population ends up residing in slums in inhuman conditions. As a result, urban poverty and hunger are increasing in many developing countries. Lack of basic amenities like safe drinking water, proper housing, drainage and excreta disposal make this population vulnerable to infections which further compromises the nutrition of those living in the slums. It is projected that more than half of the Indian population will live in urban areas by 2020 and nearly one third of this urban population will be of slum dwellers. $^{3}$ The ongoing process of rapid urbanization has deleterious repercussions on health and nutrition especially for children and pregnant women. Malnutrition in young children and pregnant women has long-term negative effects on physical and cognitive development of foetus and young children. Addressing nutritional problems of urban poor is therefore must for overall development of the country. ${ }^{4}$

Malnutrition rates remain alarming, nearly half of all deaths in children under five are attributable to under-nutrition, translating into the loss of about three million young lives a year. Under-nutrition puts children and pregnant women at greater risk of dying from common infections, increases the frequency and severity of such infections, and delays recovery. ${ }^{5}$

The interaction between under-nutrition and infection can create a potentially lethal cycle of worsening illness and deteriorating nutritional status of both children and pregnant women. Poor nutrition in

\footnotetext{
* Corresponding author.

E-mail address: tennychell@gmail.com (T. Khongrangjem).
} 
the first 1000 days of a child's life can also lead to stunted growth, which is associated with impaired cognitive ability and reduced school and work performance. ${ }^{6}$

We are still far from a world without malnutrition. While the 2018 edition of the joint malnutrition estimates illustrates that stunting prevalence has been declining since the year 2000, nearly one in four 151 million children under five were stunted in 2017 and 51 million suffered from wasting. Meanwhile, the number of overweight children worldwide has remained stagnant for more than a decade. The healthcare services are rendered to both rural and urban areas, public healthcare services are most predominant in the rural and private sector in the urban areas.

Measures of child under-nutrition are used to track development progress. In the post-2015 development era, estimates of child malnutrition will help determine whether the world is on track to achieve the Sustainable Development Goals - particularly, goal 2 to "end hunger, achieve food security and improved nutrition, and promote sustainable agriculture".

Our health system has so far accorded higher priority to rural population as rural populations far outnumber the urban and generally believed to have poorer access to health facilities. The urban sector however, now needs increasing attention and organization. It is obvious that the interventions to combat malnutrition should be specific for the targeted population and directed at the quantitatively important modifiable determinants of nutritional status. The quantitative importance of a factor is dependent on its individual effect, magnitude and prevalence; however, issues such as cost-effectiveness, cultural acceptability, and political feasibility are also important determinants of any intervention program.?

Introduction of complimentary and quality supply of supplementary food could be one way of assessing the community development. Availability of Anganwadi centres in the urban slums should be enhanced and community awareness should be generated from time to time.

Addressing the problem in the geography of Nongstoin Town:

Nongstoin town covers a total population of 1.8 lakhs out of which $22 \%$ are residing in the urban slum areas with very poor environmental and living conditions. There are at present 8 Anganwadi centres run by ICDS (Integrated Child Development Services) but most of the other facilities and services are still deprived in the centres.

Assessing the services provided at the centres would help us in promoting quality services and thereby the trend of the illness could be lowered down as compared to the present.

Monitoring of growth and development chart of the beneficiaries would enable us to provide a precise prevalence and incidence and thereby interventions have to be made. Interventions could be in the form of supplementary food and education, health hygiene and providing them basic amenities.

The percentage of malnourished and deficiency disorders as one of the indicators could be shared with the District Health Society and the office of the Community Development Programme Officer, Nongstoin for necessary information and action.

In the jurisdiction of Nongstoin, a lot of issues must be addressed at all levels with nutrition being at the core and the mortality rates due to the former being the highest in the entire state of Meghalaya. Studies have been done at national and regional level but not in the local context. Such a study would impact the health system and other governed authorities dealing with the development of the community to know the ground realities and to construct effective measures for the upliftment of the community in general.

Malnutrition in the vulnerable groups of children and pregnant women was observed to be one of the major factors for child mortality and maternal mortality in developing countries with a relatively higher prevalence in India. The urban slum dwellers are the most vulnerable groups, denied of healthcare services. The aim/objective of the study is to assess Malnutrition and its underlying causes among vulnerable populations dwelling in the urban slums of Nongstoin Town.

\section{Materials and methods}

\subsection{Study design, setting and sample size}

The study adopted was a cross-sectional study conducted in an urban slum of Nongstoin town from June-August 2018 in the Anganwadi centres. The sample size was carried out among 420 children under 5 years and 88 pregnant women at $95 \%$ confidence interval and $5 \%$ error also accounting for $10 \%$ attrition and missing data.

\subsection{Inclusion criteria and exclusion criteria}

The study participants included children under five years of age and pregnant women of Nongstoin Urban Slum. A total number of 420 participants of children under five years of age and 88 pregnant women participants were involved in the study. Children with immune deficiency disorders and pregnant women with gestational diabetes and hypertension were excluded from the study.

\subsection{Data collection methods}

A semi-structured questionnaire was used to obtained information from the study participants. Anthropometric measurements and blood haemoglobin level were carried out using Haemoglobinometer rapid test kit following with the standard methods available at the centre and at slum level. The data included weight, recumbent length, and height. Weight was measured with the help of salter weighing machine. Height was measured against a non-stretchable tape fixed to a vertical wall with the participant standing on the level of the surface. Leaning length was measured by using an infant measuring board. Blood Haemoglobin level was assessed using haemoglobinometer. $\mathrm{Hb}$ estimation was done using rapid test Haemoglobinometer (Accu Check Mission Haemoglobin Test strip). $\mathrm{Hb}$ assessment based on readings from the Accu Check with the following references: Severe Anaemia $(\mathrm{Hb}$ level $<6 \mathrm{mg} / \mathrm{dl}$, Moderate Anaemia (Hb level:6-9 mg/dl), Mild Anaemia (Hb level: $9-12 \mathrm{mg} / \mathrm{dl}$ ) Normal Haemoglobin level (Hb $>12 \mathrm{mg} / \mathrm{dl})$.

\subsection{Analysis}

The SPSS 16 for Windows was used to analyse the data. Through descriptive statistics, demographic, level of malnutrition of under five children, levels of anaemia of pregnant women and underlying causes of malnutrition were described and expressed as frequencies and percentages.

\subsection{Ethical consideration}

Permission from the Locality headman of Nongstoin Urban and The District Medical and Health officer, West Khasi Hills District, Nongstoin has been taken and approved for carrying out the study for the betterment of the community. Participation was voluntary. Informed consent and assent were obtained from all individual participants before the data collection. Confidentiality of the data was guaranteed.

\section{Results}

The demographic data of the two population group studies was shown in Tables 1 and 2. Table 1 shows the frequency Percentage table of the demographical distribution of Children under 5 years and Table 2 shows the frequency Percentage showing the levels of Malnutrition of Children under five years. Out of 420 participants 238 (56.67\%) children found severely malnourished and remaining $182(43.33 \%)$ of children were not in good health, most of them were found to have 
Table 1

Frequency Percentage table showing demographical distribution of Children under 5 years.

\begin{tabular}{lll}
\hline Variable & & $\mathrm{N}(\%)$ \\
\hline Socio-demographic Variables & 0-6 Month & $47(11.2 \%)$ \\
& 7-11 Month & $41(9.8 \%)$ \\
& 12-23 Month & $34(8.1 \%)$ \\
& 24-35 Month & $66(15.6 \%)$ \\
& 36-47Month & $60(14.3 \%)$ \\
Gender & 48-59Month & $172(41 \%)$ \\
& Male & $233(55.5 \%)$ \\
Religion & Female & $187(44.5 \%)$ \\
& Christian & $394(93.8 \%)$ \\
& Niamtre & $20(4.8 \%)$ \\
\hline
\end{tabular}

$\mathrm{N}=$ Number.

$\%=$ Percentage.

Table 2

Frequency Percentage table showing the levels of Malnutrition of Children under five years.

\begin{tabular}{ll}
\hline Level of Malnutrition & N (\%) \\
\hline Severe Malnutrition & $238(56.7 \%)$ \\
Moderate Malnutrition & $162(38.6 \%)$ \\
No Malnutrition & $20(4.7 \%)$ \\
\hline
\end{tabular}

$\mathrm{N}=$ Number.

$\%=$ Percentage.

Table 3

Frequency Percentage table showing the levels of Anaemia of Pregnant women.

\begin{tabular}{lll}
\hline Type of Anaemia & Haemoglobin level & N (\%) \\
\hline Normal & $>12 \mathrm{~g} / \mathrm{dl}$ & $3(3.4 \%)$ \\
Mild Anaemia & $9-12 \mathrm{~g} / \mathrm{dl}$ & $22(25 \%)$ \\
Moderate Anaemia & $7-9 \mathrm{~g} / \mathrm{dl}$ & $49(55.68 \%)$ \\
Severe Anaemia & $<7 \mathrm{~g} / \mathrm{dl}$ & $14(15.92 \%)$
\end{tabular}

$\mathrm{N}=$ Number.

$\%=$ Percentage.

Table 4

Frequency percentage table showing the underlying cause of Malnutrition.

\begin{tabular}{ll}
\hline Cause of Malnutrition & $\mathrm{N}(\%)$ \\
\hline Poor Health Hygiene & $398(94.8 \%)$ \\
Improper sanitation & $17(4.05 \%)$ \\
Unsafe drinking water facilities & $3(0.71 \%)$ \\
others & $2(0.44 \%)$ \\
\hline
\end{tabular}

$\mathrm{N}=$ Number.

$\%=$ Percentage.

border line malnutrition and 49 (55.68\%) were found to be moderate anaemic (Hb level:6-9 mg/dl) and $3(3.4 \%)$ found to be having normal Haemoglobin level ( $\mathrm{Hb}>12 \mathrm{mg} / \mathrm{dl})$. Children in urban slums were not attending schools as their parents are usually labourer, who are depending on their daily wages and even they are uneducated and not aware of the importance of education. Lots of children were seen playing around their parents during their work time on construction sites which are harmful to them. Poor Health Hygiene, improper sanitation and unsafe drinking water facilities were found to be the underlying causes of Malnutrition. They are prone to hundreds of diseases around them. (see Table 3 and Table 4)

\section{Discussions}

Most of the children who were found to be malnourished may be due to the reason that during data collection, these children were found more as playing outside the homes and in the periphery of the slums. A study done in Haryana state recorded that people living in urban slums have $48 \%$ prevalence of tobacco chewing which ultimately increases oral cancer among the community which leads to a socioeconomic burden on the family. ${ }^{8} \mathrm{~A}$ study done in Indore slums suggested that dental caries prevalence is $73 \%$ in which required immediate treatment for their oral health. ${ }^{9}$ One more study was done in Barely (U.P.) showed that mean height and weight of the students were lower as compared to CDC guidelines for children and study also supported that education level is one of the significant factors for nutritional stability of children. ${ }^{10}$ Nutrition is one of the major factors for health and well-being of the individual. Malnutrition is one of the major issues in public health especially in countries which are in developing phase. ${ }^{11}$ A study done in western Maharashtra suggested that children who are under 5 years of age living in urban slums have a major problem of malnutrition, which was predominantly seen in the girl child. The study suggested that more focus was needed for nutrition of children especially for girls, educating their mothers and educating them about family planning. ${ }^{12}$ It was observed in a study done by Kulkarni MV et al., in the urban slums that with an increase in the education level of girls there is a significant decrease in anaemia problem. ${ }^{13}$ Educated girls were more aware of their nutritional status and this further helps in taking care of the nutritional status of their household members. One more study done by Bhattacharyya $\mathrm{H}$ et al., supported that education is a key concept in the urban slums by which various problems can be resolved. The study shows a significant association between nutritional level and mother's literacy level. ${ }^{14}$ One more study done in urban slums in Pondicherry area of south India observed that people were having huge burden of disease like diarrhoea, ARI and malnutrition. ${ }^{15}$ Study done by Acharya et al. in Bikaner district of Rajasthan on under 5-year age group showed that malnutrition and malnourishment were observed more in males as compare to females and $25.1 \%$ children were observed wasting and children with underweight observed $37.6 \%$ in male and $26.2 \%$ in female. ${ }^{16}$ Most of the study participants in the study were poor in nutritional status and underprivileged of education and better living conditions. There is an urgent need for developing a program such as skills-based nutrition education, fortification of food items, maintain proper hygiene, improved knowledge on proper nutrition and healthy eating habit and awareness on the harmful effects of open defecation. The health indicators and overall development indices are very poor. They are far away from good health and education. There must be a program for making people aware of good health and for maintaining proper hygiene among the community. As this study was conducted in urban slums setting, children of all age group were not included equally as most of the places people refused to allow/bring their children for taking measurements and some pregnant women were not found at home during the data collection. As National Nutrition Mission (NNM) is yet to be implemented in Meghalaya, The findings from the study will be shared with the concern district officials so that collaborative efforts and measures to be taken in order to curb the malnutrition problem of the vulnerable groups.

\section{Acknowledgement}

The authors would like to express greetings to the children and pregnant women of Nongstoin urban slums for their keen and active participation in the study. The authors would also like to express gratitude to the o/o District Medical and Health Office, Nongstoin and the Headman of New Nongstoin urban slum for their continuous support throughout the study. The authors declared no funding and no conflict of interest. 


\section{References}

1. National Family Health Survey (NFHS-2), India, 1998-99. Mumbai: International Institute for Population Sciences and ORC Macro. 2000; 2000.

2. Gopalan C. The urban challenge-health/nutrition implications. In: NFI-archives. Available from: URL: http://www.nutrition_foundationofindia.orgi_ARCHIVES/ APR92_A.HTM. Accessed November 20, 2003.

3. National Nutrition Monitoring Bureau. Report on Urban Population. Hyderabad: National Institute of Nutrition; 1984.

4. Ray SK, Roy P, Deysarkari S, Lahiri A, Mukhopadhaya BB. A cross sectional study of undernutrition in 0-5 yrs. age group in an urban community. Indian J Matern Child Health. 1990;1:61-62.

5. Nutrition Foundation of India. Profiles of Undernutrition and Underdevelopment: Studies of Poor Communities in Seven Regions of the Country, NFl Scientific Report. vol. 8. New Delhi: Media Workshop; 1988.

6. Shah D, Sachdev HPS. Nutritional problems in children: Indian Scenario. Pediatr Clin India. 2001;36:1-23.

7. Department of Women and Child Development. Ministry of Human Resource Development. India Nutrition Profile. New Delhi: Government of India; 1998.

8. Unger A. Children's health in slum settings. [online] Adc.bmj.com. Available at:. http://adc.bmj.com/content/98/10/799.short; 2017, Accessed date: 12 October 2017.

9. Gupta V, Yadav K, Anand K. Patterns of tobacco use across rural, urban, and urban- slum populations in a North Indian community. Indian $J$ Community Med. 2010;35:245-251.

10. Srivastava A, Mahmood SE, Srivastava PM, Shrotriya VP, Kumar B. Nutritional status of school-age children - a scenario of urban slums in India. Arch Public Health. 2012;70:8.

11. Parthasarathy A. Partha's fundamentals of pediatrics. Protein-Energy Malnutrition: Assessment by History and Clinical Examination. first ed. New Delhi: Jaypee Brothers; 2007:108 Chap.5.

12. Patel KA, Langare SD, Naik JD, Rajderkar SS. Gender inequality and bio-social factors in nutritional status among under-five children attending anganwadis in an urban slum of a town in Western Maharashtra, India. J Res Med Sci. 2013;18:341-345.

13. Anon. [online] Available at:. http://file:///G:/Articles/Pendings/Slums/3-1_108111.pdf; 2017, Accessed date: 12 October 2017.

14. Bhattacharyya $H$, Barua A. Nutritional status and factors affecting nutrition among adolescent girls in urban slums of Dibrugarh, Assam. Natl J Community Med. 2013;4:35-39.

15. Upadhyay R, Chinnakali P, Bhilwar M, et al. Prevalence of malnutrition, acute respiratory infections, and diarrhea in children aged 1-5 years in urban slums of Puducherry, South India. Int $J$ Contemp Pediatr. 2015;2:37-41.

16. Acharya R, Meena R. A descriptive cross-sectional study to assess the prevalence of mal-nutrition in children under five years age in rural community Bikaner, Rajasthan. Int J Community Med Public Health. 2016;3:299-302. 